\title{
Zeittafel der wichtigsten Ereignisse im Nahen Osten 1957-1960
}

Januar-April 1957: Nachwirkungen der Suezkrise

Mărz 1957: Ende des anglo-jordanischen Vertrags

April 1957: politische Krise in Jordanien; König Hussein setzt die jordanische Verfassung außer Kraft

Juli-August 1957: Intervention der britischen Streitkräfte in Oman zur Unterstützung des Sultan von Muskat gegen Aufständische im Landesinneren

August-Oktober: Krise um die Regierung Syriens im Zeichen des Ost-West Konflikts

Ab Oktober 1957: "Sputnik Schock"; enge Koordination der angloamerikanischen Strategie im Nahen Osten

Februar 1958: Gründung der Vereinigten Arabischen Republik (VAR) zwischen Ägypten und Syrien, und der Arabischen Föderation (Arab Union) zwischen den Haschemiten Jordaniens und des Irak

Mai-Juli 1958: Verfassungskrise und drohender Bürgerkrieg im Libanon

14. Juli 1958: irakischer Staatsstreich; Auflösung der Arabischen Föderation; daraufhin erfolgen anglo-amerikanische Interventionen in Jordanien und im Libanon.

Ab 19. Juli bis Mitte August 1958: Gipfeldiplomatie Chruschtschows; Auseinandersetzungen über die Nahostkrise im Rahmen der UNO

21. August 1958: Arabische good neighbourliness Resolution vor der UNOVollversammlung verabschiedet

22. Oktober 1958: letzter Rückzug der anglo-amerikanischen Truppen aus dem Libanon und Jordanien. Mr. Spinelli der UNO in Amman

November 1958: Anfang von Weizenlieferungen der USA an die VAR 
6.November 1958: König Hussein wird im syrischen Luftraum auf dem Weg nach Europa von syrischen Mig-Jagdflugzeugen zur Umkehr zurück nach Amman gezwungen.

Januar-März 1959: ideologische Auseinandersetzungen um Sozialismus und Selbstbestimmung zwischen Nasser und Chruschtschow

Ende Februar 1959: Ratifizierung des Anglo-Egyptian Agreement zur Regelung der durch die Suez-Intervention entstandenen Schäden und Regreßansprüche

7.-8. März 1959: Mosulaufstand der arabischen Nationalisten mit Unterstützung der VAR gegen das Regime Abdul Karim Qasims

24. März 1959: Austritt des Irak aus dem Bagdadpakt

April 1959: Gründung des Arab Petroleum Congress in Kairo

Mai 1959: Großbritannien verkauft Waffen an den Irak

14.-15. Juli 1959: Unruhen von Kirkuk: politisch-ethnische Auseinandersetzungen zwischen Kommunisten, Turkomanen und Kurden. Verhandlungen zwischen der Iraq Petroleum Company (IPC) und der irakischen Regierung beginnen.

8. Oktober 1959: Attentat auf Ministerpräsident Qasim in Bagdad

Anfang Dezember 1959: Wiederaufnahme der diplomatischen Beziehungen zwischen London und Kairo (Tausch vonChargé d'affaires)

5. Januar 1960: Zulassung politischer Parteien im Irak; die Irakische Kommunistische Partei (ICP) wird verboten

9. Januar: zweite Bauphase des Assuan-Damms am Nil mit sowjetischer Unterstützung wird von Präsident Nasser eröffnet

August 1960: Gründung der Organisation of Petroleum Exporting Countries (OPEC) 
September 1960: Begegnung Nassers und Macmillans bei der UNO in New York; König Hussein nimmt diplomatische Beziehungen mit Bagdad in New York wieder auf; Gründung der Kuwait National Oil Company 